\title{
Advanced Nanofiber Materials and Systems: Solving Global Issues
}

Bin Ding ${ }^{1}$

(c) Donghua University, Shanghai, China 2020

Recently, the textile industry is considered as a new driving force for the world economic growth point, especially inspired by the emerging boom of nanofibers and smart textiles. Fiber materials not only meet people's needs for home textile in daily life but also are widely used in hightech fields. As a new kind of fiber material, the diameter of nanofibers has been reduced from the micron order of traditional fibers to nanoscale. The structural characteristics of nanofibers, such as high specific surface area, high porosity and high channel connectivity, endow the nanofibers many unique properties and expand their application fields into medical and health, environment and energy, national defense and military industry, and other high-tech fields.

In recent years, the United States, Germany, China and other countries have made policies to preferentially develop technical textile industry. For example, the US established a new Revolutionary Fiber and Textile Manufacturing Innovation Institute that would develop advanced fibers and textiles to be used in military, apparel, and other industries. Teams of manufacturers, universities, and non-profit organizations are being invited to compete for the $\sim \$ 150$ million funding by proposing advanced research undertakings designed to support the expansion of manufacturing in the US Germany has put forward the Industry 4.0 project, in which a very important section is the FutureTEX project, also called Europe's textile future. One important focus within the FutureTEX project is the development of textile projects of the future with new functions and application areas in the technical textiles sector. These are, for instance, textile electronics, high performance composites and textile materials for energy generation and storage. In addition, China has also issued the "textile industry development plan (2016-2020)", in which the manufacturing technology of nanofibers was proposed as the breakthrough point of key projects of textile science and technology innovation.

Bin Ding

binding@dhu.edu.cn

1 Donghua University, Shanghai, China
Therefore, we can believe that in a near future a wide range of industries are expected to benefit from these revolutionary fibers and textiles, including apparel, consumer products, automotive, medical devices, and consumer electronics.

To showcase recent advances this newly renovated field, we present this special issue of Advanced Fiber Materials on the topic of "Advanced Nanofiber Materials and Systems". The issue presents the most recent contributions of the field and highlights the hot topics in the area of sewage treatment, air filtration, electrocatalysis, biodegradation, photocatalysis, high temperature insulation and etc.

To close, we hope that this issue provides stimulating highlights of this interdisciplinary research frontier, which has demonstrated promising applications. We are most appreciative for the kind support from the editorial team of Advanced Fiber Materials, in particular Prof. Meifang Zhu. We would also like to express our gratitude to the colleagues who have shared their insights in this exciting and explorative volume of electrospinning, fibers and textiles.

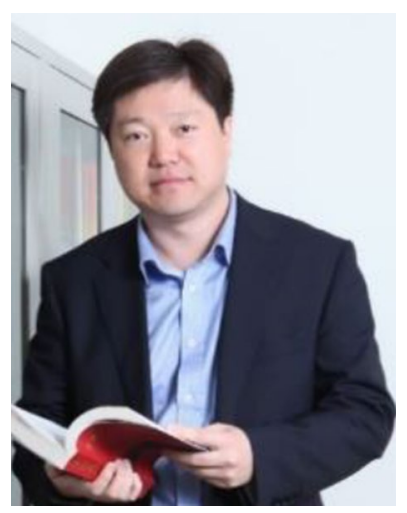

Bin Ding received his $\mathrm{Ph} . \mathrm{D}$. degree from Keio University in Japan at 2005. After 2 years of post-doctoral in Keio University (2005-2007) and a year of postdoctoral in the University of California at Davis (2007-2008), Dr. Ding stated his career as a Professor of Materials Science in Donghua University in 2008. Dr. Ding has made the contributions to the controllable fabrication and multifunctionalities of electrospun nanofibrous materials. He discovered the design and fabrication of $1 \mathrm{D}$ flexible ceramic nanofibers, novel 2D nano-nets, and 3D nanofibrous aerogels for applications of high-temperature insulation, air filtration, waterproof and breathable fabrics, oil/water emulsion separation, sound absorption, etc. 